\title{
Productivity in the Telework Era - A New Leadership Perspective
}

\author{
Andreea Bichel ${ }^{1}$, Andrei Cepoi ${ }^{2}$, Enas Aboura ${ }^{3}$ and Bogdan Frățiloiu ${ }^{4}$ \\ 1)2334) The Bucharest University of Economic Studies, Bucharest, Romania. \\ E-mail: andreea_bichel@yahoo.com; E-mail: idandrei@gmail.com \\ E-mail: enaso1993aboura@gmail.com; E-mail: alexbogdan1977@gmail.com
}

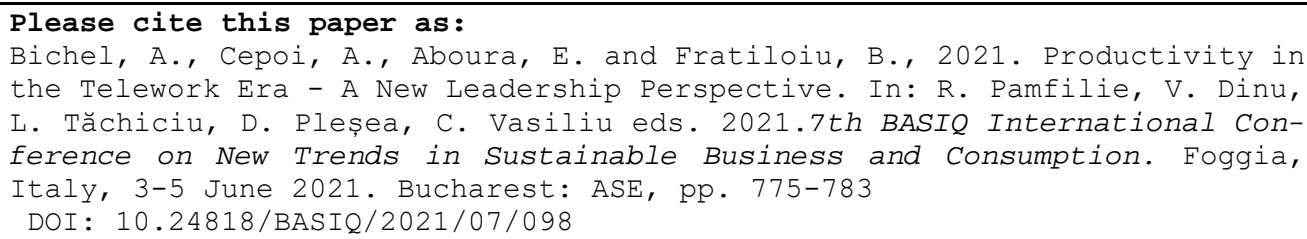

\begin{abstract}
Digitalization has been a debated subject in the $21^{\text {st }}$ century, especially during the SARS-CoV-2 pandemic when telework has become the base pillar for sustainable economy. This is the reason why, in this paper, the authors are analyzing the interplay between leadership, digitalization and how these two concepts are affecting the productivity in the business world. Starting from the recent articles and studies, our focus is to investigate how the organizations are implementing digital transformation, while aiming for better results and outcomes.
\end{abstract}

The analysis was carried out by referring to international literature for which the authors have enumerated different ways and situations where productivity was affected by telework; nevertheless, given that the pandemic is not over yet and that the timeframe these studies for mass remote working are less than a few years, there is a lot of room for further research on the effect of remote working, connected to productivity when longer periods are used as reference.

By exploring the results of the literature review and studies performed on different industries and in different countries, as well as by running a quantitative analysis of leaders' perception toward digitalization, telework and productivity in Romania, the authors identified a viable, long-lasting or even permanent trend for many leaders - to continue to work remotely as a beneficial and much better business plan with positive results in productivity.

Furthermore, the article develops a better understanding of future leadership trends and at the least, point toward three fundamental objectives specified as follows: identifying the growth rate of teleworking in the last two years, identifying specific decisions of organizations and leaders willing to prevent decreased productivity levels by changing their processes, and identifying possible new leadership trends for post pandemic business sustainability.

Keywords: Leadership; digitalization; productivity; sustainability; SARS-CoV-2.

DOI: $10.24818 / B A S I Q / 2021 / 07 / 098$

\section{Introduction}

Many articles, studies and books have been describing the leadership styles, competences, and values of the practitioners; during the last years, all concepts suffered different changes and updates along with the dynamic environment we all live in. Starting with the economy evolution, the generations and trends, leadership had different perfectible practices and methods.

Right now, as the entire society is learning to adapt to this unprecedented $21^{\text {st }}$ century crisis, that had a worldwide impact across all areas of interest (economy, governments, communities), we encountered 
increasing social differences, modified status quo of all aspects of life and even a different interest to new models of business.

Digitalization is an extensive process where "a firm employs digital technologies, to develop a new digital business model that helps create and appropriate more value for the firm" (Verhoef, et al., 2019). This new process will affect operational routines, and even business decisions and capabilities ( $\mathrm{Li}$, et al., 2018). Leaders should take a moment for creating a consensus of interpretation for the existing crisis within the organizations, while obtaining a shared and tight agreement on the vision and actions to be taken for full commitment (Carrington, Combe and Mumford, 2019).

According to Carrington, Combe and Mumford (2019), the risk is including the bivalency of this process as the senior leadership is a strong pillar and have a key-role to play. Therefore, we are expecting a leadership cultural legacy in terms of new business reality by following the changes that occurred due to the pandemic.

\section{The relationship between digitalization and leadership in times of pandemic}

Digitalization is an ardent topic these days as the governments, companies and even citizens have embraced this concept, especially nowadays. In the context of leaders, digitalization is known as a corporate instrument used for value creation or for day-to-day tasks. Executive leaders have noticed the companies do not operate isolated from what is happening around the world in terms of development, change or even pandemics. The opposite is true due to the influence and impact of economic institutions have in the era of digitalization. Therefore, change and orientation toward a new leadership style is necessary for including the benefits and advantages involved in this shift.

Beginning from 2019, digital transformation has been explained and defined as an implementation that can improve business processes and support the profit and loss statement and operational efficiency by using process optimization as the basic pillar (Cenamor, Parida and Wincent, 2019). Digitalization was an incredible worldwide force in 2020 even until the global pandemic completely transformed it. Today, digitalization is not just a source of innovation, as specialists refer to digitalization on a requirement level (Mitsuru, 2020).

The main connection toward digitalization and leadership is the new policy of working from home or telework. Studies have been conducted to investigate and capture to what extent the attitude the mangers have toward telework can make it more difficult to adopt it in organizations. The results revealed that personal belief-oriented factors such as self-perception of self-efficacy and facilitation conditions have a strong influence on the perceived ease of telework use. To put it differently, the results confirmed what the literature hypotheses related to management issues have become the barrier for telework programs while also, on the other hand as executives become more familiar with telework and see positive experiences emerging out of it, the adoption of telework tends to increase (Silva, Montoya and Valencia, 2019).

A different approach when assessing telework was focused more on what are the life stage employees are and how does that affect them, examples included gender, marital status, or parenthood; specifically, irrespective of gender and marital status, parents are less likely to telework compared to those without children. Regarding individuals without children, single individuals are more likely to telework than married ones, and males more likely than females. In contrast, for individuals with children, the partnered parents are more likely to telework than single parents, and females more likely than males. Our findings suggest that as the most important feature in family-life stages, children play a vital role in telework behavior (Zhang, et al., 2020).

When it comes to flexible work arrangements, we understand that this means giving the employees the possibility of moving away from regular working hours of traditional office locations. According to studies connecting preferences of leaders toward telework point out that different leadership styles tend to prefer or not teleworking - looking now only from the perspective of output controls, we can see the tendency that managers who focus more on output control will be more willing to favor teleworking empowering employees to have more autonomy, while on the other hand the managers who actively 
monitor performance and micromanage employees will be less likely to favor teleworking (Groen, 2018).

However, not all reports share the same insights and a different report from World Economic Forum suggests that $78 \%$ of the business leaders interviewed belied that the hybrid and work from home programs will have a negative impact on productivity. This is a result of mental health and well-being difficulties as well as distractions connected to childcare or connectivity. The Future of Jobs report also found that about $60 \%$ of works from high-income countries like Switzerland or US cannot work remotely while economies such as Egypt or Bangladesh the percentages increase to $80 \%-90 \%$. One-third of the leaders have also replied that they are taking steps to create a sense of belonging and community with their employees in the online space (Whiting, 2020).

Different studies have proposed and tested models of leadership which can be applied during telework and they are focusing on the ability of the teleworking employee namely competence or incompetence levels and their social saturation or isolation on one side and the role of the leader, such as to incorporate the teleworker to the team or expect move in the teleworker's social isolation or develop the teleworker's relationship and skill or finally, focus on upgrading the teleworker's skills (Wojcak, 2016).

Regular challenges that affected employees who had to extensively work remotely, and for whom this was not the default work schedule, include the lack of designed home office space that resulted in improvised working setups and the closure of schools that forced parents to supervise their children also during standard work hours. A different study looks into how mindfulness practices can help employees not with the logistical challenges but rather how they internalize more from building a stronger psychological framework. The study demonstrates that mindfulness might help employees in three ways: facilitating psychological detachment from work, improve attention to work related tasks and better help them recover from Zoom and screen fatigue (Toniolo-Barrios and Pitt, 2020). Therefore, studies have been conducted to investigate and capture to what extent the attitude the mangers have toward telework can make it more difficult to adopt it in organizations.

\section{Telework - Productivity connection translated within the pandemic business environment}

In this part of the article, the authors have investigated how remote working is affecting the level of productivity that employees have consider first that productivity is a key success objective in most of the businesses. Research has been conducted to reflect on insights connected to the rapid adoption changes and the effects on the productivity of the mass remote working policies and emerging behaviors, the IT systems and business procedures that had been changed to better suite remote work, why remote working is better suited for certain industries or specific tasks and impractical for other and what produces different changes in productivity from both leadership and management side as well as logistics and personal conditions of remote workers.

There is no doubt that different changes can have a stressing effect on the employees and during the pandemic they included worries about safety, layoffs or taking care of children who are attending distance learning; according to State of Work survey, $84.5 \%$ of business do intend to continue to offer the possibility for workers to continue to work remotely as an option while some like Twitter go even further and have instituted permanent remote working policies; first and foremost we need to agree on what productivity actually symbolizes so that we can assess the impact that working remotely has on it - to put it simply, productivity is how efficient people are at completing tasks, how effective they are to produce a desired result (Nevogt, 2020).

The pandemic has accelerated the number of employees working from home or remotely for example in USA pre-pandemic the number of employees who were not working from office premises were between $5 \%$ and $16 \%$ however this has increased to $65 \%$ according to studies in 2020; Initial finding have shown that productivity has not changed or has even increased at least in the first months following the decisions for mass remote working for employees and surveys have pointed out that it is largely influenced by company culture and its existing leadership (Kazi, 2021). 


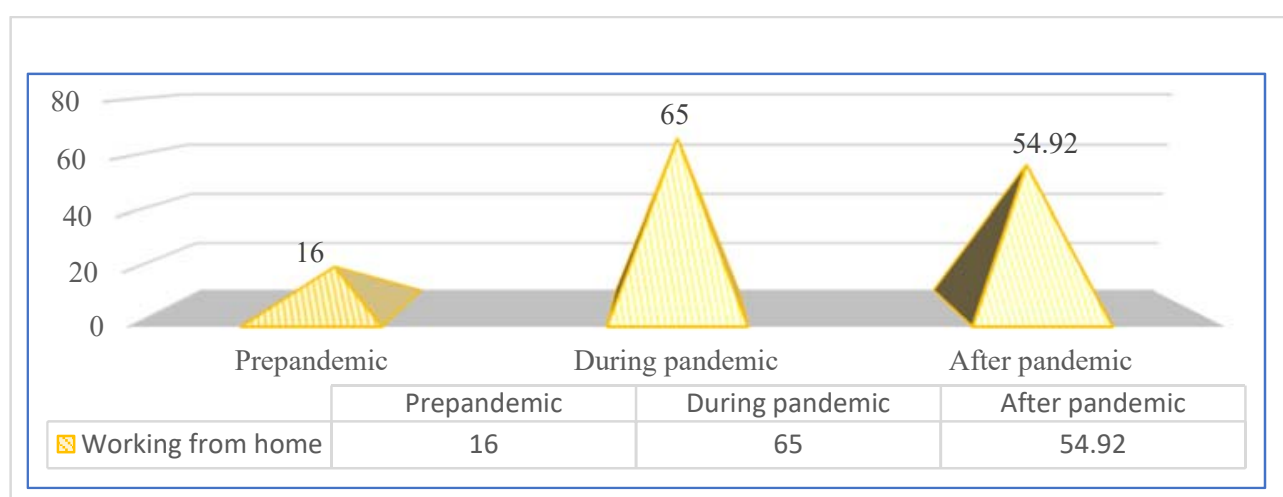

Figure no. 1. The evolution of telework levels in USA during the SARS-CoV-2 crisis Source: Developed by the authors according to Chandni, 2021

Because remote working was not a common practice in the majority of companies many leaders and employees did not have the necessary data to test and improve working from home policies and methods and had to rapidly adopt it with the learning curve associated with any new competence and behavior (Nemțeanu and Dabija, 2020). A study was done before the pandemic where $42 \%$ of the managers answered that the monitoring of the productivity levels of their own employees is the biggest challenge for them and this has outweighed concerns linked with communication or interpersonal connection; The possible distractions or different schedules employees had to adapt to while working from home has created an emerging need of flexibility for them and so a hypothesis can be made that if managers are checking the levels of productivity by monitoring attendance to virtual meetings or oncalls during business hours, then they might use the wrong measuring methods. As a result, one alternative to use the full potential of technology is not to use it as surveillance but rather create trust and use tech for remote collaboration opportunities; Alternatively, while surveillance can be counterproductive research show that employees want to be visible and the need for recognition has increased by levels of 30\% during remote working (Alper-Leroux, 2021).

Companies both who offered IT applications for remote collaboration systems and teleworking tools have seen the demand for their products increase exponentially, Zoom for example saw the number of downloads in March 2020 to multiply 14 times in US, and between 20 and 55 times in European countries such as UK, Spain and Italy; not only that the adoption of Zoom has increased exponentially but also other IT companies started putting more effort into such remote collaboration products and innovate the space to ride this trend. Nevertheless, while the adoption of these platforms was critical for employees to continue to work remotely as they have done in the offices and so that their productivity not to be affected, the technology has leveled the fields and knowledge, and know-how remains one of the most important competitive advantage a company has; focus should be kept on that they can exert it at the same level and not be affected using more modern collaboration tools and systems (Kodama, 2020).

There are however aspects we need to deep dive to assess the conditions different surveys are being conducted and how the results could be affected by them. To illustrate such an example, a work remotely experiments followed by a survey at the Trip.com Group Chinese company, which is the biggest online travel company in China, have shown that for the first nine months since testing work from home there was no drop in productivity, but in contrast the productivity went up by $20 \%$. While this has come as a pleasant surprise for the management, we need to state that to benefit from the work remotely policy the participant had to meet several requirements including to not have children, to have an additional room besides the bedroom as well as to have a good quality internet. Unfortunately, we cannot rely only on this data as the pandemic begins and all people were put into lockdown and work from home, these three conditions could not be met by all employees and as such, the results in productivity can be different (Myska, 2020).

Another way to look at research is to run them similarly but in different time periods - as such, another interesting research that studied knowledge workers in particular both in 2013 and again in 2020 found that among other things, the lockdown helped people focus more on the tasks that really matter, helped 
employees take more responsibility on their own schedules while doing $50 \%$ more activities because of their own choose while half as many for the ones someone else has asked them to do it (Birkinshaw and Stach, 2020).

Studies have shown that productivity can be increased also by working more hours, so attention also needs to be given when comparing productivity changes when employees work from office and work from home. One study has stated that remote workers work an average of 1.4 more days per month, which adds to an additional 3 weeks per year. Also tied or not with more time spent working, the results also showed that $29 \%$ of them struggle with work-life balance while $31 \%$ answered that they should take a day off to support their mental health; suggestion on how remote workers can stay productive because of Airtasker survey includes taking breaks spread throughout the day and using time-management technique such as Pomodoro, set a fixed interval for work hours and keeping a to-do list; the study also showed that the biggest benefit is not having to commute to work while the biggest challenge relates to connecting with coworkers remotely (Caramela, 2020).

Other surveys seem to back up the results that employees tend to work more hours when they work remotely and as such a survey done with CoSo Cloud employees shows that $23 \%$ of them are willing to work longer hours to get the tasks done, $52 \%$ are less likely to take time off while $30 \%$ believe they accomplish more in less time. Another survey done by FlexJobs on remote workers states that $66 \%$ of participants agree that their productivity improves while not in the office while $76 \%$ believe there are fewer distractions outside the office, however we must consider the aspect that one thing is measuring how the participants perceive the impact it had on their productivity and quite another for productivity to be measured by proper methods and afterwards compared with the time when work was done in the office; interesting enough we are moving more and more into a generation change in the field of work where more roles are being filled by millennials demographic group, $85 \%$ of them prefer working from home all the time while now for examples according to a study in America almost half of the millennial workers are freelancing. Perhaps even more interesting survey done by Stanford University found that employee's turnover or attrition was reduced by half when they were offered remote work options, and this is perhaps one of the most important aspects managers have as priority (Andersen, 2021).

Because different cultures have different behaviors, work patterns and preferences, in a sense cultural difference, when it comes to human interaction and how work gets done, one hypothesis that the authors wanted to research about was if teleworking has different effects on employees and their productivity when we research different countries around the world (Acosta-Prado, et al., 2020).

A different research has also looked at how indoor environmental quality (noise, air quality, natural light) affects productivity when working in the office or from home; findings include that worker's productivity was most affected by the noise levels while the air quality aimed more at the comfort and health and given that homes and apartments are not a professional environment, we can see how the noise levels can be out of the teleworker's ability to influence especially with neighbors and other sources of noise (Rasheed, Khoshbakht and Baird, 2021).

In a research done in Japan, the main findings reveal that appropriate teleworking hours actually increase labor productivity while longer hours have the opposite effect; teleworking seems to increase life satisfaction and this has a positive effect on labor productivity, however it also increases the stress in work-life unbalance; nevertheless the stress does not automatically have a negative effect on labor productivity the finding also mentioned; the study also points out that telework is more efficient to improve labor productivity if employees commute more than one hour or by crowded public transportation during rush hours in Japan; finally extra tasks like trivial duties arise irresponsible of schedules that are given by managers or colleagues are more likely to be avoided during teleworking however, the study also demonstrates the importance of these tasks (Kazekami, 2020).

In Sweden, a study showed that from a transportation perspective, there is more optimism regarding teleworking as it leads to reduced travel demand, the increase usage of active transport modes and the relief of congestion is something that is a positive aspect in the lives of teleworkers (Elldér, 2020).

Another research from Portugal on how productivity is affected by remote electronic access has shown that the possibility of working remotely specifically connected to remote access, is more likely to be harmful for productivity specially for non-exporting, small firms that are not in R\&D and harmful for 
employees with what is considered a below-average skill level and competence. (Monteiro, Straume and Valente, 2021)

Yet, from another angle and focusing more toward leadership, a research looked into what are the connection between enjoyment (gamification) of work and its effects on productivity and the role of the leader; first and foremost gamification is an internal process in which activities, processes and organizational structures are transformed with the aim to achieve an experience much like playing games - as such the study has determined that using gamification to effect the enjoyment of work is producing positive effects also to productivity but mainly to employees with leadership responsibilities (Gerdenitsch, et al. 2020).

There are surveys which are already looking beyond the current pandemic and what could be the most optimum balance between the amount of time people spend in the office or at home and unilaterally employees want flexibility, which is having the best of both worlds, a hybrid model where the need dictates if the employee will work from home or office and not the other way around; Different points are being made that a solution implemented across industries and without taking note of the specificity of the job or the tasks, is detrimental to productivity: more than half the workforce cannot work remotely or in other words their job or tasks cannot be done remotely from utilizing only a computer and a solid internet connection and examples include the need for collaborating with other people, utilizing specialized machinery, the working location is not an office in the first place or the task is linked with making deliveries; There are additional aspects to be considered such as even though some activities can be done remotely, the levels of productivity and quality has declined considerably, and an example is teaching. The industries that have a tail wind however are finance and insurance, management, business services and IT. Perhaps one of the biggest impediments to productivity that is technical is the connectivity aspect; researchers found that only $65 \%$ of Americans surveyed said they have a good enough fast internet service that can help with video conference calls and US is a developed country, we can only imagine the situation is far worse in developing economies and their effects on productivity (Lund, et al., 2020).

Now more toward the future, a study concerning the post-pandemic aftermath, focused on the deployment of smart offices and information communication technology; in this regard, it demonstrates how this makes it possible to meet the needs of the organization and increase the levels of productivity by providing an immediate benefit, creating results from the interrelation between technology and employee and by redefining labor mix and organizational structure (Papagiannidis and Marikyan, 2020).

\section{Research Methodology}

The authors proceeded an analysis of a worldwide relevant literature in the field of leadership, digitalization, and productivity and how these three terms are connected. After understanding the existence of few empirical data, the authors decided to focus on a descriptive paper, and both a qualitative and quantitative analysis. Therefore, the main research instruments used in the construction, selection and development of this paper is the descriptive analysis, followed by the critical analysis of the factors involved in and a survey run on a represented number of managers and leaders of organizations in Romania, in order to probe both the existing research and if the literature findings do match, as well as testing a new hypothesis concerning digitalization, telework and the changes in productivity.

In the end, the authors will present their own observations regarding the direct contact with telework, having in mind that all these studies for mass remote working are less than a few years and understanding that there is a lot of room for further research on the effect of remote working connected to productivity when longer periods will be used as reference.

\section{Results and discussions}

As we have identified from our literature research this point toward that if leadership in companies favors remote working then their teams will follow in the same direction; we have concluded that focusing our survey on leaders and managers only, will give us a good indication on how digitalization and teleworking cascades within the entire companies. 
When it comes to our survey, which was conducted to analyze how managers and leaders have experienced digitalization and teleworking during the pandemic in Romania, the demographics show that $50 \%$ were aged 30 to 39 , approximately $70 \%$ of them were women and almost $90 \%$ have been working between 3 to 4 days remotely.

When we look at the results of how productivity has changed for them during the pandemic, it does confirm what we investigated in the majority of the global studies, which is that for the majority of participants, more than $35 \%$ of them mentioned that their productivity has increased slightly, followed by $25 \%$ who sees no changes in their productivity levels. Interesting enough when asked what the effects on productivity in their own teams were, the leaders have provided almost identical answers and results.

Perhaps one of the most important questions we have asked leaders to probe the studies conducted, was how difficult were for leaders to find a balance between work time and free time while working from home; here as well the results confirmed that one of the most difficult aspect of teleworking is separating and balancing work and personal time - our results show that over 35\% of our responders have found this difficult with almost $15 \%$ stating that it has been very difficult for them.

Finally, when asked what were the types of activities or programs that had a positive impact on their productivity, the leaders have given examples such as the flexibility of standard working hours, wellbeing programs, subscriptions to mindfulness apps, home desk furniture and short Friday working hours.

As a conclusion, the authors have enumerated different ways and situations where productivity can be affected and mentioned several studies and their insights; the results of the survey done for Romanian leaders do seem to back up the general existing studies investigated and provide new evidence on novel ideas on how productivity can increase also during telework; nevertheless, given that the pandemic is not over yet and that the timeframe for these studies on mass remote working are less than a few years, there is a lot of room for further research on the effect of remote working connected to productivity when longer periods will be used as reference.

\section{Conclusions}

First, the authors have drawn the main characteristics of the leadership digitalization from a sample of 25 related papers. The repetitive characteristics inside the articles were disregarded, resulting in 13 main impacts of the digital leadership concept and its connection with productivity.

Second, the authors identified a conceptual link where they underlined the characteristics match between leadership, digitalization, and productivity. The main antecedents start from economic capabilities to organizational capabilities (employees wellbeing due to social saturation or isolation) and environmental capabilities.

Thirdly, a quantitative analysis was done with the respondents being selected from the leaders and managers of several multinationals from Romania and the results were connected with previous research on the topics of digitalization, telework and how productivity is affected because of that.

In the end, the authors attest that obtaining business sustainability implies a series of characteristics that need to be highlighted in the digitalization of leadership; followed by adopting these characteristics, especially during and inside the tumultuous business environment in the time of the pandemic.

During digitalization, leaders had changed their business model as they had to include a few extra processes for their remote workforce:

- New policies including flexible workhours and clear expectations for communicating remote

- Work computers, home desk furniture and other devices for their teams

- Wellbeing programs including access to mindfulness apps

- Onboarding or offboarding employees

- Access and configuration to business and collaboration applications

- Setting Network/VPN access and secure login capabilities 
The authors concluded that the greatest challenge for leaders is to create a sense of belonging and community with their employees and teams in the online space; arguing that digitalization could be the sustainable answer to the leadership trends post SARS-CoV-2 crisis.

\section{Acknowledgement}

This paper was co-financed by The Bucharest University of Economic Studies during the PhD program.

\section{References}

Acosta-Prado, J.C., Sandoval-Reyes, J.G. and Sanchís-Pedregosa, C., 2020. Job Demands and Recovery Experience: The Mediation Role of Heavy Work Investment. Amfiteatru Economic, 22(Special Issue No. 14), pp.1206-1226.

Alper-Leroux, C., 2021. Rethinking Productivity In A Remote Working World, [online] Available at: $<$ https://www.forbes.com/sites/forbeshumanresourcescouncil/2021/01/07/rethinking-productivityin-a-remote-working-world/?sh=781eda422373> [Accessed 15 March 2020].

Andersen, J.J., 2021. 9 Research-Based Facts That Prove Remote Teams are The Future of Work, [online] Available at: <https://www.timedoctor.com/blog/remote-teams-future-of-work/> [Accessed 15 March 2020].

Birkinshaw, J. and Stach, J.C.P., 2020. Research: Knowledge Workers Are More Productive from Home, [online] Available at: $<$ https://hbr.org/2020/08/research-knowledge-workers-are-more-productive-from-home > [Accessed 15 March 2020].

Caramela, S., 2020. Working from Home Increases Productivity, [online] Available at: $<$ https://www.businessnewsdaily.com/15259-working-from-home-more-productive.html $>$ [Accessed 15 March 2020].

Carrington, D.J., Combe, I.A. and Mumford, M.D., 2019. Cognitive shifts within leader and follower teams: Where consensus develops in mental models during an organizational crisis. The Leadership Quarterly, 30, pp.335-350.

Cenamor, J., Parida, V. and Wincent, J., 2019. How entrepreneurial SMEs compete through digital platforms: The roles of digital platform capability, network capability and ambidexterity. Journal of Business Research, 100, pp.196-206.

Elldér, E., 2020. Telework and daily travel: New evidence from Sweden. Journal of Transport Geography, 86, Article number: 102777.

Gerdenitsch, C., Sellitsch, D., Besser, M., Burger, S., Stegmann, C., Tscheligi, M. and Kriglstein, S., 2020. Gamification at Work: Effects on Work Enjoyment and Productivity and the Role of Leadership Responsibilities. Electronic Commerce Research and Applications, 43, Article number: 100994.

Groen, B.A.C., van Triest, S.P., Coers, M. and Wtenweerde N., 2018. Managing flexible work arrangements: Teleworking and output controls. European Management Journal, 36(6), pp.727-735.

Kazekami, S., 2020. Mechanisms to improve labor productivity by performing telework. Telecommunications Policy, 44(2), Article number: 101868.

Kazi, C., 2021. Remote Work Productivity Study Finds Surprising Reality: 2-Year Analysis, [online] Available at: $<$ https://www.greatplacetowork.com/resources/blog/remote-work-productivitystudy-finds-surprising-reality-2-year-study $>$ [Accessed 15 March 2020].

Kodama, M. 2020. Digitally transforming work styles in an era of infectious disease. International Journal of Information Management, 55, Article number: 102172.

Larson, L. and De Church, L.A., 2020. Leading teams in the digital age: Four perspectives on technology and what they mean for leading teams. The Leadership Quarterly, 31(1), Article number: 101377.

Li L., Su, F., Zhang, W. and Mao, J.Y., 2018. Digital transformation by SME entrepreneurs: A capability perspective. Information Systems Journal, 28(6), pp.1129-1157. 
Lund, S., Madgavkar, A., Manyika, J. and Smit S., 2020, What's next for remote work: An analysis of 2,000 tasks, 800 jobs, and nine countries, [online] Available at: $<$ https://www.mckinsey.com/featured-insights/future-of-work/whats-next-for-remote-work-an-analysis-of-2000-tasks-800-jobsand-nine-countries $>$ [Accessed 15 March 2020].

Mitsuru, K., 2020, Digitally transforming work styles in an era of infectious disease, International Journal of Information Management, 55, Article number: 102172.

Monteiro, N.P., Straume, O.R. and Valente, M., 2021. When does remote electronic access (not) boost productivity? Longitudinal evidence from Portugal. Information Economics and Policy, Article number: 100923.

Myska, S., 2020. The remote work experiment that upped productivity 13\%, [online] Available at: $<$ https:/www.bbc.com/worklife/article/20200710-the-remote-work-experiment-that-made-staffmore-productive $>$ [Accessed 15 March 2020].

Nemțeanu, M.S. and Dabija, D.C., 2020. The Influence of Heavy Work Investment on Job Satisfaction and Turnover Intention in Romania. Amfiteatru Economic, 22(Special Issue 14), pp.993-1013.

Nevogt, D., 2020. Are remote workers more productive? We've checked all the research so you don't have to, [online] Available at: <https://blog.hubstaff.com/remote-workers-more-productive/> [Accessed 15 March 2020].

Papagiannidis, S. and Marikyan, D., 2020. Smart offices: A productivity and well-being perspective. International Journal of Information Management, 51, Article number: 102027.

Rasheed, E.O., Khoshbakht, M. and Baird, G., 2021. Time spent in the office and workers' productivity, comfort and health: A perception study. Building and Environment, 195, Article number: 107747.

Silva, C.A., Montoya, I.A.R and Valencia, A.J.A., 2019. The attitude of managers toward telework, why is it so difficult to adopt it in organizations? Technology in Society, 59, Article number: 101133.

Toniolo-Barrios, M. and Pitt, L., 2020. Mindfulness and the challenges of working from home in times of crisis, Business Horizons, 64(2), pp.189-197.

Verhoef, P.C., Broekhuizen, T., Bart, Y., Bhattacharya, A., Dong, J. Q., Fabian, N. and Haenlein, M., 2019. Digital transformation: A multidisciplinary reflection and research agenda. Journal of Business Research, 122, pp.889-901.

Whiting, K., 2020. Most leaders think remote working will hit productivity - this is why, [online] Available at: $<$ https://www.weforum.org/agenda/2020/10/remote-working-productivity-future-of-jobs/> [Accessed 15 March 2020].

Wojcak, E., Bajzikova, L., Sajgalikova, H. and Polakova, M., 2016. How to Achieve Sustainable Efficiency with Teleworkers: Leadership Model in Telework. Procedia - Social and Behavioral Sciences, 229, pp.33-41.

Zhang, S., Moeckel, R., Moreno, A.T., Shuai, B. and Gao, J., 2020. A work-life conflict perspective on telework. Transportation Research Part A: Policy and Practice, 141, pp.51-68. 